\title{
Repurposing therapeutics to identify novel inhibitors targeting 2'-O-ribose methyltransferase nsp16 of SARS-CoV-2
}

Yuanyuan Jiang, Lanxin Liu, Morenci Manning, Madison Bonahoom, Aaron Lotvola and ZengQuan Yang

Department of Oncology, Wayne State University School of Medicine, Detroit, MI, USA. Molecular Therapeutics Program, Barbara Ann Karmanos Cancer Institute, Detroit, MI, USA.

Corresponding author: Zeng-Quan Yang, Ph.D., Barbara Ann Karmanos Cancer Institute, 4100 John R Street, HWCRC 815, Detroit, MI 48201 Tel: (313)576-8339; Fax: (313)576-8029; Email: yangz@karmanos.org

Key Word: SARS-CoV-2, nsp16, methyltransferase, virtual screening 


\begin{abstract}
SARS-CoV-2, an emerging coronavirus, has spread rapidly around the world, resulting in over three million cases and more than 220,000 deaths as of April 30, 2020. Effective treatments and vaccines for SARS-CoV-2 infection do not currently exist. Previous studies demonstrated that nonstructural protein 16 (nsp16) of coronavirus is an S-adenosyl methionine (SAM)-dependent 2'-O-methyltransferase (2'-O-MTase) that has an important role in viral replication and prevents recognition by the host innate immune system. In the present study, we employed structural analysis, virtual screening, and systematic drug repurposing approaches to identify "approved" drugs which can act as promising inhibitors against nsp16 2'-O-MTase of SARS-CoV-2. We provide a ranking of the predicted binding affinities of 1,380 top hit compounds corresponding to 967 drugs. Furthermore, we have calculated various structural parameters of our top-ranking drugs, including Hesperidin and Sonedenoson, which have previously been clinically approved or investigated for treating various other diseases. Our studies provided the foundation to further test and repurpose these candidate drugs experimentally and clinically for COVID-19 treatment.
\end{abstract}




\section{Introduction}

Three coronaviruses (CoVs): severe acute respiratory syndrome coronavirus (SARS-CoV-1), Middle East respiratory syndrome coronavirus (MERS-CoV), and the recently identified SARSCoV-2 in December 2019, have caused deadly pneumonia in humans since the beginning of the 21st century [1-3]. The SARS-CoV-2 causes coronavirus disease-19 (COVID-19) with influenza-like symptoms ranging from mild discomfort to severe lung injury and multi-organ failure, eventually leading to death. As of April 30, 2020, more than three million $(3,175,207)$ COVID-19 cases were reported worldwide, and more than 220,000 $(224,172)$ patients have died (https://www.who.int/emergencies/diseases/novel-coronavirus-2019). Effective treatments and vaccines for SARS-CoV-2 infection do not currently exist. Thus, it will be of great benefit to identify and repurpose already well-characterized compounds and approved drugs for use in combating COVID-19.

CoVs are positive-sense RNA viruses that replicate in the cytoplasm of infected cells. Replication and transcription of the CoV RNA genome are achieved by a complex RNA replication/transcription machinery, consisting of at least 16 viral nonstructural proteins (nsp) [3, 4]. Previous studies demonstrated that nsp16 proteins of SARS-CoV-1 and MERS-CoV have methyltransferase (MTase) activities that catalyze methylation of the first transcribed nucleotide at the ribose 2'-O position (2'-O-Me) [5-7]. The 2'-O-Me of virus cap RNAs protects itself from degradation by 5'-3' exoribonucleases, ensures efficient translation, and helps to prevent recognition by the host innate immune system [8]. The importance of nsp16 2'-O-MTase activity for $\mathrm{CoV}$ infection and pathogenesis was previously documented by in vitro and in vivo studies [8-11]. For SARS-CoV-1, the absence of nsp16 2'-O-MTase activity results in significant attenuation characterized by decreased viral replication, reduced weight loss, and limited breathing dysfunction in mice [12]. In addition, nsp16 down-regulates the activities of innate immune sensing factors: retinoic acid-inducible gene I (RIG-I) and melanoma differentiationassociated gene 5 protein (MDA5) [12, 13]. Thus, inhibition of nsp16 2'-O-MTase activities should restrain viral replication and enable recognition by the host innate immune system, making the nsp16-MTase a promising target for the identification of new anti-SARS-CoV-2 drugs. 
In the present study, we employed structural analysis, virtual screening, and systematic drug repurposing approaches to identify "approved" drugs which can act as promising inhibitors against nsp16 2'-O-MTase of SARS-CoV-2. We first performed comparative analysis of primary amino acid sequences and crystal structures of seven human CoVs and defined the key residues for nsp16 2-O'-MTase functions. From the virtual screening against nsp16 2'-O-MTase of SARS-CoV-2, we provide a ranking of the predicted binding affinities of 1,380 top hit compounds corresponding to 967 "approved" drugs. Furthermore, we have calculated various structural parameters of our top-ranking drugs. Our studies provided the foundation to further test and repurpose these candidate drugs experimentally and clinically for COVID-19 treatment.

\section{Results}

Comparative sequence and structure analysis of nsp16 2'-O-MTases

To identify inhibitors targeting nsp16, we first performed comparative analysis of primary amino acid sequences and crystal structures of seven human CoVs. Supplementary Table 1 lists the detailed genome and protein information that were employed in this study. In primary amino acid sequences, nsp16 of SARS-CoV-2 was found to be $93.3 \%$ identical to SARS-CoV-1, but only 56.6-65.9\% identical to five other human CoVs, including MERS-CoV, and four least harmful HCoV-OC43, -HKU1, -NL63, and -229E. The nsp16 proteins belong to a class of Sadenosyl methionine (SAM)-dependent 2'-O-MTases present in all life forms, and they all contain the conserved catalytic KDKE motif (K46, D130, K170, and E203 in SARS-CoV-2) (Figure 1A \& B) [5, 6, 14]. Previous studies in SARS-CoV-1 demonstrated that the 2'-O-MTase activity is completely abolished by single mutation of any residue in this KDKE motif [14].

We next analyzed crystal structures of nsp16s obtained from SARS-CoV-2, SARS-CoV-1, and MERS-CoV that are available in RCSB Protein Data Bank (PDB) (Supplementary Table S1) [5, $6,15]$. The three-dimensional (3D) structures of nsp16s were solved in complex with nsp10 that functions as a stimulatory factor to regulate 2'-O-MTase function (Supplementary Figure S1) [5, $6,15]$. Structural alignment was performed using TM-align, an algorithm for sequence- 
independent protein structure comparisons [16]. We revealed the highest coverage, percent identity, and structural conservation between SARS-CoV-2 and SARS-CoV-1 nsp16 bound to SAM [PDB: 6W4H: chain A (Resolution: $1.80 \AA$ ); and 3R24: chain A (Resolution: $2.00 \AA$ ), respectively], with TM-score 0.958 and Root Mean Square Deviation $(\mathrm{RMSD})=0.89$. The SARS-CoV-2 nsp16 structure is also highly similar to the MERS-CoV complex bound to SAM and a cap analogue: 7-methyl-GpppA [PDB:5YNM: chain A (Resolution: 1.68 A)], with TMscore 0.956 and RSMD=0.80 (Supplementary Figure S2). Since no structures with cap analogue or substrate RNA are available for SARS-CoV-1 and -2 nsp16 currently, the RNA binding pocket and key residues for RNA recognition were generated by the superposition of 6W4H and 5YNM. As shown in Figure 1C \& D, the conserved KDKE catalytic tetrad motif is located at the bottom of the RNA binding pocket. The KDKE might bind the first adenine nucleotide, conserved in SARS genomic and subgenomic RNAs, as the acceptor of the methyl group during methylation. Notably, previous structural and biochemical studies revealed that the nsp16 2'-OMTase activity of SARS-CoV-1 is sequence-dependent as it could only methylate m7GpppAcapped RNA, where the first nucleotide is absolutely restricted to adenosine [5, 6, 14]. Other residues including K38, Y47, Y181, and D133 are also involved in the RNA binding. Structural analysis also revealed that residues N43, Y47, G71, A72, S74, G81, D99, L100, N101, D114, and M131 coordinate SAM substrate binding in both SARS-CoV-1 and -2 through hydrogen bonds and water-mediated interactions [7].

In humans, cap methyltransferase 1 (CMTR1) is a specific 2'-O-MTase that catalyzes Cap1 methylation of mRNA $[17,18]$. We also performed comparative analysis of the crystal structures of CoV-2 nsp16 and human 2'-O-MTase CMTR1. SARS-CoV-2 nsp16 and human CMTR1 MTase domain share little primary amino acid sequence identity (12.1\%) based on the Pairwise Sequence Alignment with the Needleman-Wunsch algorithm at EMBL-EBI services. ( https://www.ebi.ac.uk/Tools/psa/). Although both contain a similar KDKE catalytic tetrad motif and a conserved folding made of a seven-stranded $\beta$-sheet surrounded by one to three helices on each side, substantial differences are found in the RNA binding groove as well as the SAM binding pocket (Figure 1C and Figure 2). In CMTR1, Cap0 binds in a deep pocket, with a triphosphate bridge and Cap1 phosphate backbone stabilized by a stack of arginine residues along the RNA binding groove [18]. In contrast, the putative RNA binding groove on SARS- 
CoV-2 nsp16 appears to be less positively charged and shallow, indicating that the binding of RNA substrate may be unstable (Figure 1C). Even though the SAM binding pocket is conserved between human and viral 2'-O-MTase, they have different structural features. In SARS-CoV-2 nsp16, the SAM binding pocket is more negatively charged than that of CMTR1. Also, the SAM binding pocket on SARS-CoV-2 nsp16 is more open and flexible comparing with that of CMTR1, which is deeper and longer (Figure 1C and 2). In this context, the difference between the structures of the human and 2'-O-MTase CMTR1 and CoV nsp16 could be exploited to develop inhibitors that could specifically block viral methyltransferases [19, 20].

\section{Virtual screening of drugs against nsp 16 of SARS-CoV-2}

We hypothesize that the small-molecule antagonists of nsp16 of SARS-CoV-2 may be repurposed to limit viral replication and/or unmask viral RNA to intracellular innate immunity. To identify new drugs that have the potential to inhibit nsp16 functions of SARS-CoV-2, we first examined the druggability of all binding sites. DoGSiteScorer (values are between zero and one) was used to calculate geometrical and physicochemical properties such as volume, depth, and hydrophobicity [21]. The SAM pocket has the highest drug score (0.85) and RNA binding pocket has a score of 0.55 in SARS-CoV-2 nsp16 (Supplementary Figure S1). The similar scores were observed in MERS-CoV nsp16 (PDB: 5YNM) that is solved in complex with both SAM and the cap RNA analogue (Supplementary Figure S1).

As the aim of this work was to identify previous clinically investigated and approved drugs for repurposing to treat COVID-19 infections, we made use of an MTiOpenScreen database Drugslib that contains 7,173 stereoisomers corresponding to 4574 "approved" drugs [22, 23]. Among them, the nsp16 natural ligand SAM, which is used for therapies against depression, liver disorders, fibromyalgia, and osteoarthritis, would serve as a positive control for virtual screening [24]. Among the five currently available nsp16 structures of SARS-CoV-2 (April 30, 2020), we selected the 6W4H PDB structure which presents the best resolution (1.8 $)$ to screen the Drugslib using the MTiOpenScreen service [22]. The computations of MTiOpenScreen were carried out with AutoDock Vina, a gradient optimization algorithm, which provided a list of the 1,500 highest-scoring compounds [22, 23, 25]. We repeated the MTiOpenScreen screening protocol three times using the $6 \mathrm{~W} 4 \mathrm{H}$ structure to ensure the reliability of the results. We found that four 
stereoisomers of SAM were ranked in the top 1,500 best compounds in all three runs, with energy equal to $-8.10 \mathrm{kcal} / \mathrm{mol}$ (Figure 3A \& B, Supplementary Table S2), indicating our positive docking predictions. Among the 1,500 top hit compounds in each screening, 1,380 compounds were shared across all three MTiOpenScreen runs with highly similar AutoDock Vina scores. Based on the means of scores, we ranked these 1380 compounds (stereoisomers) that correspond to 967 "approved" drugs (Supplementary Table S2). The top ten drugs with the highest scores were MK3207, Rimegepant, Entrectinib, Osi-027, Bolazine, R428, Hesperidin, Losulazine, Rebastinib, and Cep-32496, with the means of energy around -10.97 -10.17 $\mathrm{kcal} / \mathrm{mol}$ (Figure 3A and Table 1). Notably, there are 38 Hesperidin stereoisomers and four MK3207 stereoisomers among 1,380 hits (Figure 3A and Supplementary Table S2).

To understand previously reported pharmacological action of hit compounds, we queried the biological target and pathway classes in the Probes and Drugs Portal, in which 713 standardized (693 non-isomeric) drugs were available for these 967 drugs [26]. The top target classes of these drugs are G-protein-coupled receptors (241), catalytic receptors (139), and kinases (129). The top pathways are signal transduction (453), immune system (270), and transcription (247) (Figure 3C). For example, MK3207 and Rimegepant are calcitonin gene-related peptide receptor (CGRP) receptor antagonists, which have been clinically investigated for migraine treatment [2731]. Hesperidin possesses biological and pharmacological properties as an effective antioxidant, anti-inflammatory, anti-carcinogenic, and anti-hypertensive agent (Table 1) [32, 33].

\section{Drugs similar to ligand of nsp16}

Using the principles of structural similarity searching, analogues of natural ligand (SAM) in nsp16 might be potent inhibitors against 2'-O-MTase function. Since SAM was among our 1,380 highest-scoring compounds, we next computed the similarity between each pair of compounds using the FragFp descriptors in DataWarrior [31]. Among them, we found that seven drugs that are chemically similar to SAM, namely Gs-9667, Trabodenoson, Binodenoson, Sonedenoson, Regadenoson, Metrifudil, and Selodenoson (Figure 3A and Table 2). All seven of these drugs are adenosine receptor agonists that were clinically investigated for treating various diseases, including cardiac arrhythmias, neuropathic pain, inflammatory diseases, and cancer [34, 35]. 
Additionally, a preprint in ChemRxiv (doi.org/10.26434/chemrxiv.12021330.v1) reported that two of seven drugs, Trabodenoson and Selodenoson, are also identified as potential SARS-CoV2 nsp16 inhibitors by computing similarity between 8,085 drugs and SAM with COMPLIG program [36] .

Flexible docking simulation of candidate drugs against nsp16 of SARS-CoV-2

Rigid docking performed using Autodock Vina provided insight into the binding affinity and hydrogen bond formation of the candidate compounds on the nsp16 2'-O-MTase. Next, the top ten drugs and seven drugs structurally similar to SAM were chosen for the ligand flexible docking simulation by using the RosettaLigand program [37, 38]. RosettaLigand employs the Monte Carlo minimization protocol in which the ligand position and orientation are randomly perturbed by a small deviation $\left(0.1 \AA\right.$ and $\left.3^{\circ}\right)$. A scoring function in RosettaLigand includes an electrostatics model, an explicit orientation-dependent hydrogen bonding potential, an implicit solvation model, and van der Walls interactions [37, 38]. Rosetta's energy score (REU) of these 17 drugs were shown in Table 1 and 2. With RosettaLigand simulation, Hesperidin ranked the highest with the lowest REU among the top 10 hits obtained from the Autodock Vina screening. In the seven SAM-like drugs, similar to AutoDock Vina results, Gs-9667 had the lowest REU score (Table 2).

Binding mode analysis and intermolecular interaction of top drugs and nsp16

We next examined the interaction of these 17 drugs with key residues for nsp16 2'-O-MTase function. We found that Hesperidin, Osi-027, Gs-9667, and Sonedenoson have many hydrogen bonding or hydrophobic interactions with key functional residues involving in 2'-O-MTase function, which are represented in Figure 4 and Supplementary Figure S3. Hesperidin forms hydrogen bonds with N43, K46, D99, L100, C115, D130, Y132, and K170, and hydrophobic interactions with M131. Osi-027 forms hydrogen bonds with N43, K46, D99, L100, N101, Y132, and K170 and hydrophobic interactions with M131, C115, and F149. Gs-9667 forms hydrogen bonds with L100, D114, C115, and Y132, and hydrophobic interactions with L100, M131, and Y132. Sonedenoson forms hydrogen bonds with N43, K46, D75, D99, D130, and 
K170, and hydrophobic interactions with L100 and M131. Notably, Hesperidin and Sonedenoson form hydrogen bonds with three key residues of KDKE motif: K46, D130 and K170. Based on the ligand-interface interactions, these drugs, notably Hesperidin and Sonedenoson, are worthy of future experimental studies targeting the nsp16 of SARS-CoV-2.

\section{Discussion}

In the present study, we analyzed structural features and functional determination of 2'-OMTase nsp16 of SARS-CoV-2, the newly-identified Betacoronavirus genera, which causes the devastating COVID-19. The nsp16 has a druggable pocket, which is associated with ligand binding and enzymatic activity. By using high-throughput virtual screening against nsp16 of SARS-CoV-2, we have ranked approximately 1,000 therapeutic drugs, including several clinically approved drugs that have the potential to inhibit nsp16 2'-O-MTase and be repurposed for COVID-19 treatment.

Methylation of RNA, which occurs in all kingdoms of life, plays important roles in RNA metabolism, processing, stability, nuclear export, translation efficiency, and others [39-42]. 2'-OMe is predominantly found in rRNA and tRNA of bacteria and eukaryotes, as well as in the 5' mRNA Cap of higher eukaryotes [43, 44]. In humans, five 2'-O-MTases [FtsJ RNA methyltransferase homolog 1 (FTSJ1), FTSJ2, FTSJ3, CMTR1, and CMTR2] have been reported to catalyze 2'-O-Me of various RNAs, regulate important cellular functions, and are associated with developmental disorders and cancer [45-48]. Mutations of FTSJ1, a tRNA 2'-O-MTase, cause autosomal-recessive intellectual disability [49-51]. FTSJ2 (also known as MRM2) is a mitochondrial rRNA methyltransferase [52]. Human FTSJ3, which likely catalyzes 2'-O-Me of both rRNA and internal sites of mRNA, is a potential regulator of breast cancer progression [53]. Furthermore, FTSJ3 catalyzes 2'-O-Me of HIV RNAs and leads to the inhibition of innate immune sensing and response [45]. Both CMTR1 and CMTR2 catalyze mRNA cap methylation, CMTR1 for cap1 and CMTR2 for cap2. Notably, CMTR1 has previously been identified as ISG95, a protein implicated in the response to interferon treatment and viral infection [54-57]. A very recent study in influenza A virus revealed that loss of CMTR1 in host cells inhibits viral 
replication and up-regulates anti-viral genes [58]. Thus, 2'-O-MTases have critical roles in viral replication and anti-viral immune response.

Both SARS-CoV-1 and -2 have a single-stranded RNA with 30,000 nucleotides with 5'-cap structure and 3'-poly-A tail (Figure 1A) [1-3]. Many RNA viruses, including CoVs, replicate in the cytoplasm using their own viral 2'-O MTases, such as nsp16, which catalyze the formation of cap structures on viral mRNA that mimic those present on host mRNAs [59, 60]. Previous studies on SARS-CoV-1 and MERS-CoV demonstrated that targeting nsp16 has the potential to interfere with viral replication both at the level of inhibition of the replication process and in promoting intracellular recognition and immune response to viral RNA species [8-10]. Zust et al. determined the role of nsp16 in the viral replication cycle and found that 2'-O-Me acts as a recognition marker that helps the host cell to recognize its own RNA species. Infection studies comparing wild-type virus and nsp16 mutant CoVs showed that the mutant viruses had decreased replication kinetics but induced higher levels of interferon (IFN) - $\beta[12,13]$. Thus, nsp16-MTase is a promising target for identification of drugs for virus infections, including SARS-CoV-2.

Using virtual screening, we have ranked the predicted binding affinities of approximately 1,000 therapeutic drugs that have potential to inhibit nsp16 2'-O-MTase function. The top hits include MK3207, Rebastinib, Hesperidin, Entrectinib, and Osi-027, which have been experimentally and clinically investigated for treatment of various diseases. Both MK-3207 and Rimegepant are highly-selective CGRP antagonists shown to have potent action against migraine [27-31]. Notably, the orally disintegrating tablet (ODT) formulation of Rimegepant received its first global approval in the USA for the acute treatment of migraine in adults [61]. The exact mechanism of Rimegepant action has yet to be fully characterized, but it has been shown that Rimegepant is a substrate for p-glycoprotein [61]. Entrectinib is an orally available, potent and selective inhibitor of the tyrosine kinases tropomyosin receptor kinases (TRK)A/B/C $[62,63]$. Entrectinib was granted breakthrough U.S. FDA approval in 2019 for TRK fusionpositive cancers [62]. Additionally, OSI-027, which allosterically binds to the catalytic site of the kinase domain of mammalian target of rapamycin (mTOR), has demonstrated potent anti-tumor 
activity in tumor xenografts and is currently undergoing investigation in Phase I clinical trials of patients with advanced cancer $[64,65]$.

Among the top hits, one of the most promising drugs is Hesperidin, a citrus bioflavonoid, which possesses antioxidant, anti-inflammatory, antiviral, and anticarcinogenic properties [33, 66]. It was used as the pharmaceutical raw material in the pharmaceutical industry and is one of the main components of a Chinese medicine, beniol [67]. Importantly, Hesperidin had demonstrated antiviral properties in in vitro models against influenza A virus (H1N1) by stimulating cellautonomous immunity through interferon gene expression [68]. Hesperidin also showed promising anti-viral activity against EV-A71 (enterovirus) by enhancing cell survival and reducing viral infection in cells by more than $80 \%$, however the mechanism was not fully characterized [69]. In this study, we found that Hesperidin was the top scoring drug that has the ligand-residue interactions that are critical for nsp $162^{2}$ '-O-MTase functions. It will be very interesting to determine whether Hesperidin directly binds nsp16 of SARS-CoV-2 with various biochemical approaches and its antiviral activity in cellular and animal models related to COVID-19.

All seven drugs that have similar structures to the nsp16 natural ligand SAM are agonists of the adenosine receptors (ARs). One of them with top AutoDuck and Rosetta scores is Gs-9667, which was clinically investigated for treating Type 2 diabetes. In a phase I study, GS-9667 was generally considered safe and well tolerated [70]. Another interesting hit, Sonedenoson, which facilitates wound healing by regulating the inflammatory response and tissue generation, was evaluated in phase II clinical trials for the treatment of diabetic foot ulcers [70]. Additionally two others, Trabodenoson and Selodenoson, were also reported in a preprint of ChemRxiv (doi.org/10.26434/chemrxiv.12021330.v1) [36]. Given the similar results from both studies, these compounds would be reasonable drugs for further experimental investigation in inhibiting nsp16 2'-O-MTase function.

In conclusion, we analyzed structural features and functional determination of 2'-O-MTase nsp16 of SARS-CoV-2 and employed virtual screening approach for identifying and ranking approximately 1,000 drugs that have the potential to impact nsp16 function. Among them, we 
found that at least 17 drugs, including Hesperidin and Sonedenoson, merit further testing and repurposing experimentally and/or clinically for COVID-19 treatment.

\section{Material and Methods}

\section{$\underline{\text { Sequence and structure analysis }}$}

The primary amino acid sequences of seven human CoV nsp16 proteins and human CMTR1 were retrieved from the NCBI (National Center for Biotechnology Information) Database, and Supplementary Table 1 lists the detailed genome and protein ID for these 2'-O-MTases. The protein sequences were aligned using Clustal Omega (https://www.ebi.ac.uk/Tools/msa/clustalo/), and was presented with the ESPript 3.0 program (http://espript.ibcp.fr/ESPript/ESPript/). Crystal structures of three CoV nsp16s and human CMTR1 were obtained from RCSB Protein Data Bank [5, 6, 15], and analyzed with PyMOL and UCSF Chimera programs. Structural alignment was performed using TM-align algorithm [16].

\section{$\underline{\text { Virtual screening }}$}

Crystal structure (6W4H) of SARS-CoV-2 nsp16 with $1.8 \AA$ resolution was prepared with UCSF Chimera programs for virtual screening against a Drugs-lib that contains 7,173 stereoisomers corresponding to 4,574 "approved" drugs in MTiOpenScreen service [22, 23]. The Drugs-lib is generated from four compound databases of the "drug" subset of the ChEMBL database, the "approved" subset of DrugBank, the DrugCentral database, and the "approved" SuperDrug2 database [22]. For the MTiOpenScreen Vina docking, the (x, y, z) grid center coordinates used for SAM binding pocket of $6 \mathrm{~W} 4 \mathrm{H}$ are $(83.7,14.8,27.7)$, and the size of the search space was set to $20 \AA$ x $20 \AA$ x $20 \AA$. The MTiOpenScreen screening was repeated three times, and the compounds shared across all three runs was analyzed by DataWarrior, PyMOL, and UCSF Chimera programs. Fragfp descriptors were used to compute the similarity between each pair of compounds [31]. The targets and pathways of identified candidate compounds were analyzed by querying Probes and Drugs Portal. 
Flexible docking simulation in RosettaLigand program

Ligand flexible docking simulation were performed by using the RosettaLigand program that employs the Monte Carlo minimization protocol [37, 38]. In the first, low-resolution stage, the ligand is placed near the SAM binding pocket, where it is perturbed 50 times and rotated 1000 times in a random direction. The best-scoring models are filtered by root-mean-square deviation to eliminate near duplicates and one of the remaining models is selected at random. To ensure that the ligand did not "walk away" from the protein, the ligand is moved towards the protein. The second, high-resolution stage employs the Monte Carlo minimization protocol in which the ligand position and orientation are randomly perturbed by a small deviation $\left(0.1 \AA\right.$ and $\left.3^{\circ}\right)$; receptor side chains are repacked using a rotamer library; the ligand position, orientation, and torsions and protein side-chain torsions are simultaneously optimized using quasi-Newton minimization and the end result is accepted or rejected based on the Metropolis criterion. Scoring uses the full-atom Rosetta energy function with softened van der Waals repulsion [37, 38]. The full repack makes 1000 random rotamer substitutions at random positions and accepts or rejects each on the Metropolis criterion. Rotamer trials choose the single best rotamer at a random position in the context of the current state of the rest of the system, with the positions visited once each in random order. Six cycles of rotamer trials and a full repack after every three cycles are performed. The third and final stage is a more stringent gradient-based minimization of the ligand position, orientation, and torsions and receptor torsions for both side chains and backbone. Scoring uses the same Rosetta energy function, but with a hard-repulsive van der Waals potential, which creates a more rugged energy landscape that is better at discriminating native from non-native binding modes $[37,38]$. The entire structure is then scored using the partial covalent interactions energy function, which is developed to score H-bonds more accurately.

\section{Conflict of interest}

The authors have no competing interests to declare.

\section{Acknowledgments}

This work was partially supported by grants from the Department of Defense (DoD) Breast 
Cancer Program BC161536, Elsa U. Pardee Foundation, DMC Foundation and Molecular Therapeutics Program of Karmanos Cancer Institute to Dr. Zeng-Quan Yang; and by funding from Susan G. Komen GTDR14299438 and Wayne State University Graduate School Dean Mathur Fellowship to Morenci Manning.

\section{References}

[1] F. Wu, S. Zhao, B. Yu, Y.M. Chen, W. Wang, Z.G. Song, Y. Hu, Z.W. Tao, J.H. Tian, Y.Y. Pei, M.L. Yuan, Y.L. Zhang, F.H. Dai, Y. Liu, Q.M. Wang, J.J. Zheng, L. Xu, E.C. Holmes, Y.Z. Zhang, A new coronavirus associated with human respiratory disease in China, Nature 579(7798) (2020) 265-269.

[2] N. Zhu, D. Zhang, W. Wang, X. Li, B. Yang, J. Song, X. Zhao, B. Huang, W. Shi, R. Lu, P. Niu, F. Zhan, X. Ma, D. Wang, W. Xu, G. Wu, G.F. Gao, W. Tan, I. China Novel Coronavirus, T. Research, A Novel Coronavirus from Patients with Pneumonia in China, 2019, N Engl J Med 382(8) (2020) 727-733.

[3] V. Coronaviridae Study Group of the International Committee on Taxonomy of, The species Severe acute respiratory syndrome-related coronavirus: classifying 2019-nCoV and naming it SARS-CoV-2, Nat Microbiol 5(4) (2020) 536-544.

[4] S. Perlman, J. Netland, Coronaviruses post-SARS: update on replication and pathogenesis, Nat Rev Microbiol 7(6) (2009) 439-50.

[5] Y. Chen, C. Su, M. Ke, X. Jin, L. Xu, Z. Zhang, A. Wu, Y. Sun, Z. Yang, P. Tien, T. Ahola, Y. Liang, X. Liu, D. Guo, Biochemical and structural insights into the mechanisms of SARS coronavirus RNA ribose 2'-O-methylation by nsp16/nsp10 protein complex, PLoS Pathog 7(10) (2011) e1002294.

[6] E. Decroly, C. Debarnot, F. Ferron, M. Bouvet, B. Coutard, I. Imbert, L. Gluais, N. Papageorgiou, A. Sharff, G. Bricogne, M. Ortiz-Lombardia, J. Lescar, B. Canard, Crystal structure and functional analysis of the SARS-coronavirus RNA cap 2'-O-methyltransferase nsp10/nsp16 complex, PLoS Pathog 7(5) (2011) e1002059.

[7] W. Aouadi, A. Blanjoie, J.J. Vasseur, F. Debart, B. Canard, E. Decroly, Binding of the Methyl Donor S-Adenosyl-1-Methionine to Middle East Respiratory Syndrome Coronavirus 2'O-Methyltransferase nsp16 Promotes Recruitment of the Allosteric Activator nsp10, J Virol 91(5) (2017).

[8] V.D. Menachery, K. Debbink, R.S. Baric, Coronavirus non-structural protein 16: evasion, attenuation, and possible treatments, Virus Res 194 (2014) 191-9.

[9] L. Subissi, I. Imbert, F. Ferron, A. Collet, B. Coutard, E. Decroly, B. Canard, SARS-CoV ORF1b-encoded nonstructural proteins 12-16: replicative enzymes as antiviral targets, Antiviral Res 101 (2014) 122-30.

[10] M. Sevajol, L. Subissi, E. Decroly, B. Canard, I. Imbert, Insights into RNA synthesis, capping, and proofreading mechanisms of SARS-coronavirus, Virus Res 194 (2014) 90-9. [11] S.R. Gonzales-van Horn, P. Sarnow, Making the Mark: The Role of Adenosine Modifications in the Life Cycle of RNA Viruses, Cell Host Microbe 21(6) (2017) 661-669. 
[12] V.D. Menachery, B.L. Yount, Jr., L. Josset, L.E. Gralinski, T. Scobey, S. Agnihothram, M.G. Katze, R.S. Baric, Attenuation and restoration of severe acute respiratory syndrome coronavirus mutant lacking 2'-o-methyltransferase activity, J Virol 88(8) (2014) 4251-64. [13] R. Zust, L. Cervantes-Barragan, M. Habjan, R. Maier, B.W. Neuman, J. Ziebuhr, K.J. Szretter, S.C. Baker, W. Barchet, M.S. Diamond, S.G. Siddell, B. Ludewig, V. Thiel, Ribose 2'O-methylation provides a molecular signature for the distinction of self and non-self mRNA dependent on the RNA sensor Mda5, Nat Immunol 12(2) (2011) 137-43.

[14] M. Bouvet, C. Debarnot, I. Imbert, B. Selisko, E.J. Snijder, B. Canard, E. Decroly, In vitro reconstitution of SARS-coronavirus mRNA cap methylation, PLoS Pathog 6(4) (2010) e1000863.

[15] H.M. Berman, J. Westbrook, Z. Feng, G. Gilliland, T.N. Bhat, H. Weissig, I.N. Shindyalov, P.E. Bourne, The Protein Data Bank, Nucleic Acids Res 28(1) (2000) 235-42.

[16] Y. Zhang, J. Skolnick, TM-align: a protein structure alignment algorithm based on the TMscore, Nucleic Acids Res 33(7) (2005) 2302-9.

[17] F. Belanger, J. Stepinski, E. Darzynkiewicz, J. Pelletier, Characterization of hMTr1, a human Cap1 2'-O-ribose methyltransferase, J Biol Chem 285(43) (2010) 33037-44.

[18] M. Smietanski, M. Werner, E. Purta, K.H. Kaminska, J. Stepinski, E. Darzynkiewicz, M. Nowotny, J.M. Bujnicki, Structural analysis of human 2'-O-ribose methyltransferases involved in mRNA cap structure formation, Nat Commun 5 (2014) 3004.

[19] M. Byszewska, M. Smietanski, E. Purta, J.M. Bujnicki, RNA methyltransferases involved in 5 ' cap biosynthesis, RNA Biol 11(12) (2014) 1597-607.

[20] V.B. Luzhkov, B. Selisko, A. Nordqvist, F. Peyrane, E. Decroly, K. Alvarez, A. Karlen, B. Canard, J. Qvist, Virtual screening and bioassay study of novel inhibitors for dengue virus mRNA cap (nucleoside-2'O)-methyltransferase, Bioorg Med Chem 15(24) (2007) 7795-802. [21] A. Volkamer, D. Kuhn, F. Rippmann, M. Rarey, DoGSiteScorer: a web server for automatic binding site prediction, analysis and druggability assessment, Bioinformatics 28(15) (2012) 2074-5.

[22] N. Lagarde, E. Goldwaser, T. Pencheva, D. Jereva, I. Pajeva, J. Rey, P. Tuffery, B.O. Villoutreix, M.A. Miteva, A Free Web-Based Protocol to Assist Structure-Based Virtual Screening Experiments, Int J Mol Sci 20(18) (2019).

[23] N. Lagarde, J. Rey, A. Gyulkhandanyan, P. Tuffery, M.A. Miteva, B.O. Villoutreix, Online structure-based screening of purchasable approved drugs and natural compounds: retrospective examples of drug repositioning on cancer targets, Oncotarget 9(64) (2018) 32346-32361. [24] A. Sharma, P. Gerbarg, T. Bottiglieri, L. Massoumi, L.L. Carpenter, H. Lavretsky, P.R. Muskin, R.P. Brown, D. Mischoulon, R. as Work Group of the American Psychiatric Association Council on, S-Adenosylmethionine (SAMe) for Neuropsychiatric Disorders: A ClinicianOriented Review of Research, J Clin Psychiatry 78(6) (2017) e656-e667.

[25] O. Trott, A.J. Olson, AutoDock Vina: improving the speed and accuracy of docking with a new scoring function, efficient optimization, and multithreading, J Comput Chem 31(2) (2010) 455-61.

[26] C. Skuta, M. Popr, T. Muller, J. Jindrich, M. Kahle, D. Sedlak, D. Svozil, P. Bartunek, Probes \&Drugs portal: an interactive, open data resource for chemical biology, Nat Methods 14(8) (2017) 759-760.

[27] C.A. Salvatore, E.L. Moore, A. Calamari, J.J. Cook, M.S. Michener, S. O'Malley, P.J. Miller, C. Sur, D.L. Williams, Jr., Z. Zeng, A. Danziger, J.J. Lynch, C.P. Regan, J.F. Fay, Y.S. Tang, C.C. Li, N.T. Pudvah, R.B. White, I.M. Bell, S.N. Gallicchio, S.L. Graham, H.G. Selnick, 
J.P. Vacca, S.A. Kane, Pharmacological properties of MK-3207, a potent and orally active calcitonin gene-related peptide receptor antagonist, J Pharmacol Exp Ther 333(1) (2010) 152-60. [28] I.M. Bell, Calcitonin gene-related peptide receptor antagonists: new therapeutic agents for migraine, J Med Chem 57(19) (2014) 7838-58.

[29] T. Mallick-Searle, M. Moriarty, Unmet needs in the acute treatment of migraine attacks and the emerging role of calcitonin gene-related peptide receptor antagonists: An integrative review, J Am Assoc Nurse Pract (2020).

[30] R.B. Lipton, R. Croop, E.G. Stock, D.A. Stock, B.A. Morris, M. Frost, G.M. Dubowchik, C.M. Conway, V. Coric, P.J. Goadsby, Rimegepant, an Oral Calcitonin Gene-Related Peptide Receptor Antagonist, for Migraine, N Engl J Med 381(2) (2019) 142-149.

[31] R. Croop, P.J. Goadsby, D.A. Stock, C.M. Conway, M. Forshaw, E.G. Stock, V. Coric, R.B. Lipton, Efficacy, safety, and tolerability of rimegepant orally disintegrating tablet for the acute treatment of migraine: a randomised, phase 3, double-blind, placebo-controlled trial, Lancet 394(10200) (2019) 737-745.

[32] S. Tejada, S. Pinya, M. Martorell, X. Capo, J.A. Tur, A. Pons, A. Sureda, Potential Antiinflammatory Effects of Hesperidin from the Genus Citrus, Curr Med Chem 25(37) (2018) 4929. 4945.

[33] V. Aggarwal, H.S. Tuli, F. Thakral, P. Singhal, D. Aggarwal, S. Srivastava, A. Pandey, K. Sak, M. Varol, M.A. Khan, G. Sethi, Molecular mechanisms of action of hesperidin in cancer: Recent trends and advancements, Exp Biol Med (Maywood) 245(5) (2020) 486-497.

[34] Z.G. Gao, K.A. Jacobson, Emerging adenosine receptor agonists: an update, Expert Opin Emerg Drugs 16(4) (2011) 597-602.

[35] K.A. Jacobson, D.K. Tosh, S. Jain, Z.G. Gao, Historical and Current Adenosine Receptor Agonists in Preclinical and Clinical Development, Front Cell Neurosci 13 (2019) 124.

[36] M. Saito, N. Takemura, T. Shirai, Classification of ligand molecules in PDB with fast heuristic graph match algorithm COMPLIG, J Mol Biol 424(5) (2012) 379-90.

[37] I.W. Davis, D. Baker, RosettaLigand docking with full ligand and receptor flexibility, J Mol Biol 385(2) (2009) 381-92.

[38] G. Lemmon, J. Meiler, Rosetta Ligand docking with flexible XML protocols, Methods Mol Biol 819 (2012) 143-55.

[39] H. Shi, J. Wei, C. He, Where, When, and How: Context-Dependent Functions of RNA Methylation Writers, Readers, and Erasers, Mol Cell 74(4) (2019) 640-650.

[40] R.V. Kadumuri, S.C. Janga, Epitranscriptomic Code and Its Alterations in Human Disease, Trends Mol Med 24(10) (2018) 886-903.

[41] I.A. Roundtree, M.E. Evans, T. Pan, C. He, Dynamic RNA Modifications in Gene Expression Regulation, Cell 169(7) (2017) 1187-1200.

[42] S. Li, C.E. Mason, The pivotal regulatory landscape of RNA modifications, Annu Rev Genomics Hum Genet 15 (2014) 127-50.

[43] P. Boccaletto, M.A. Machnicka, E. Purta, P. Piatkowski, B. Baginski, T.K. Wirecki, V. de Crecy-Lagard, R. Ross, P.A. Limbach, A. Kotter, M. Helm, J.M. Bujnicki, MODOMICS: a database of RNA modification pathways. 2017 update, Nucleic Acids Res 46(D1) (2018) D303D307.

[44] L. Ayadi, A. Galvanin, F. Pichot, V. Marchand, Y. Motorin, RNA ribose methylation (2'-Omethylation): Occurrence, biosynthesis and biological functions, Biochim Biophys Acta Gene Regul Mech 1862(3) (2019) 253-269. 
[45] M. Ringeard, V. Marchand, E. Decroly, Y. Motorin, Y. Bennasser, FTSJ3 is an RNA 2'-Omethyltransferase recruited by HIV to avoid innate immune sensing, Nature 565(7740) (2019) 500-504.

[46] K.W. Lee, D.F. Bogenhagen, Assignment of 2'-O-methyltransferases to modification sites on the mammalian mitochondrial large subunit $16 \mathrm{~S}$ ribosomal RNA (rRNA), J Biol Chem 289(36) (2014) 24936-42.

[47] J. Hager, B.L. Staker, H. Bugl, U. Jakob, Active site in RrmJ, a heat shock-induced methyltransferase, J Biol Chem 277(44) (2002) 41978-86.

[48] H. Bugl, E.B. Fauman, B.L. Staker, F. Zheng, S.R. Kushner, M.A. Saper, J.C. Bardwell, U. Jakob, RNA methylation under heat shock control, Mol Cell 6(2) (2000) 349-60.

[49] L.R. Jensen, L. Garrett, S.M. Holter, B. Rathkolb, I. Racz, T. Adler, C. Prehn, W. Hans, J. Rozman, L. Becker, J.A. Aguilar-Pimentel, O. Puk, K. Moreth, M. Dopatka, D.J. Walther, V. von Bohlen Und Halbach, M. Rath, M. Delatycki, B. Bert, H. Fink, K. Blumlein, M. Ralser, A. Van Dijck, F. Kooy, Z. Stark, S. Muller, H. Scherthan, J. Gecz, W. Wurst, E. Wolf, A. Zimmer, M. Klingenspor, J. Graw, T. Klopstock, D. Busch, J. Adamski, H. Fuchs, V. Gailus-Durner, M.H. de Angelis, O. von Bohlen Und Halbach, H.H. Ropers, A.W. Kuss, A mouse model for intellectual disability caused by mutations in the X-linked 2'Omethyltransferase Ftsj1 gene, Biochim Biophys Acta Mol Basis Dis 1865(9) (2019) 2083-2093.

[50] K. Freude, K. Hoffmann, L.R. Jensen, M.B. Delatycki, V. des Portes, B. Moser, B. Hamel, H. van Bokhoven, C. Moraine, J.P. Fryns, J. Chelly, J. Gecz, S. Lenzner, V.M. Kalscheuer, H.H. Ropers, Mutations in the FTSJ1 gene coding for a novel S-adenosylmethionine-binding protein cause nonsyndromic X-linked mental retardation, Am J Hum Genet 75(2) (2004) 305-9.

[51] M.P. Guy, M. Shaw, C.L. Weiner, L. Hobson, Z. Stark, K. Rose, V.M. Kalscheuer, J. Gecz, E.M. Phizicky, Defects in tRNA Anticodon Loop 2'-O-Methylation Are Implicated in Nonsyndromic X-Linked Intellectual Disability due to Mutations in FTSJ1, Hum Mutat 36(12) (2015) 1176-87.

[52] K.W. Lee, C. Okot-Kotber, J.F. LaComb, D.F. Bogenhagen, Mitochondrial ribosomal RNA (rRNA) methyltransferase family members are positioned to modify nascent rRNA in foci near the mitochondrial DNA nucleoid, J Biol Chem 288(43) (2013) 31386-99.

[53] M. Manning, Y. Jiang, R. Wang, L. Liu, S. Rode, M. Bonahoom, S. Kim, Z.Q. Yang, Pancancer analysis of RNA methyltransferases identifies FTSJ3 as a potential regulator of breast cancer progression, RNA Biol (2020) 1-13.

[54] A.I. Su, J.P. Pezacki, L. Wodicka, A.D. Brideau, L. Supekova, R. Thimme, S. Wieland, J. Bukh, R.H. Purcell, P.G. Schultz, F.V. Chisari, Genomic analysis of the host response to hepatitis C virus infection, Proc Natl Acad Sci U S A 99(24) (2002) 15669-74.

[55] G.K. Geiss, V.S. Carter, Y. He, B.K. Kwieciszewski, T. Holzman, M.J. Korth, C.A. Lazaro, N. Fausto, R.E. Bumgarner, M.G. Katze, Gene expression profiling of the cellular transcriptional network regulated by alpha/beta interferon and its partial attenuation by the hepatitis $\mathrm{C}$ virus nonstructural 5A protein, J Virol 77(11) (2003) 6367-75.

[56] S. Guerra, L.A. Lopez-Fernandez, A. Pascual-Montano, M. Munoz, K. Harshman, M. Esteban, Cellular gene expression survey of vaccinia virus infection of human HeLa cells, $\mathbf{J}$ Virol 77(11) (2003) 6493-506.

[57] T. Haline-Vaz, T.C. Silva, N.I. Zanchin, The human interferon-regulated ISG95 protein interacts with RNA polymerase II and shows methyltransferase activity, Biochem Biophys Res Commun 372(4) (2008) 719-24. 
[58] B. Li, S.M. Clohisey, B.S. Chia, B. Wang, A. Cui, T. Eisenhaure, L.D. Schweitzer, P. Hoover, N.J. Parkinson, A. Nachshon, N. Smith, T. Regan, D. Farr, M.U. Gutmann, S.I. Bukhari, A. Law, M. Sangesland, I. Gat-Viks, P. Digard, S. Vasudevan, D. Lingwood, D.H. Dockrell, J.G. Doench, J.K. Baillie, N. Hacohen, Genome-wide CRISPR screen identifies host dependency factors for influenza A virus infection, Nat Commun 11(1) (2020) 164.

[59] J.L. Hyde, M.S. Diamond, Innate immune restriction and antagonism of viral RNA lacking 2-O methylation, Virology 479-480 (2015) 66-74.

[60] R. Netzband, C.T. Pager, Epitranscriptomic marks: Emerging modulators of RNA virus gene expression, Wiley Interdiscip Rev RNA 11(3) (2020) e1576.

[61] L.J. Scott, Rimegepant: First Approval, Drugs 80(7) (2020) 741-746.

[62] A. Drilon, TRK inhibitors in TRK fusion-positive cancers, Ann Oncol 30 Suppl 8 (2019) viii23-viii30.

[63] A. Sartore-Bianchi, E.G. Pizzutilo, G. Marrapese, F. Tosi, G. Cerea, S. Siena, Entrectinib

for the treatment of metastatic NSCLC: safety and efficacy, Expert Rev Anticancer Ther (2020) $1-9$.

[64] J. Mateo, D. Olmos, H. Dumez, S. Poondru, N.L. Samberg, S. Barr, J.M. Van Tornout, F. Jie, S. Sandhu, D.S. Tan, V. Moreno, P.M. LoRusso, S.B. Kaye, P. Schoffski, A first in man, dose-finding study of the mTORC1/mTORC2 inhibitor OSI-027 in patients with advanced solid malignancies, Br J Cancer 114(8) (2016) 889-96.

[65] Z. Zou, T. Tao, H. Li, X. Zhu, mTOR signaling pathway and mTOR inhibitors in cancer: progress and challenges, Cell Biosci 10 (2020) 31.

[66] H. Parhiz, A. Roohbakhsh, F. Soltani, R. Rezaee, M. Iranshahi, Antioxidant and antiinflammatory properties of the citrus flavonoids hesperidin and hesperetin: an updated review of their molecular mechanisms and experimental models, Phytother Res 29(3) (2015) 323-31. [67] L. Bai, X. Li, L. He, Y. Zheng, H. Lu, J. Li, L. Zhong, R. Tong, Z. Jiang, J. Shi, J. Li, Antidiabetic Potential of Flavonoids from Traditional Chinese Medicine: A Review, Am J Chin Med 47(5) (2019) 933-957.

[68] Z. Ding, G. Sun, Z. Zhu, Hesperidin attenuates influenza A virus (H1N1) induced lung injury in rats through its anti-inflammatory effect, Antivir Ther 23(7) (2018) 611-615.

[69] F.J. Tsai, C.W. Lin, C.C. Lai, Y.C. Lan, C.H. Lai, C.H. Hung, K.C. Hsueh, T.H. Lin, H.C. Chang, L. Wan, J.J. Sheu, Y.J. Lin, Kaempferol inhibits enterovirus 71 replication and internal ribosome entry site (IRES) activity through FUBP and HNRP proteins, Food Chem 128(2) (2011) 312-22.

[70] P.M. Staehr, A.K. Dhalla, J. Zack, X. Wang, Y.L. Ho, J. Bingham, L. Belardinelli, Reduction of free fatty acids, safety, and pharmacokinetics of oral GS-9667, an A(1) adenosine receptor partial agonist, J Clin Pharmacol 53(4) (2013) 385-92.

\section{Figure Legends:}

Figure 1: Comparative analysis of primary amino acid sequences and crystal structures of $\mathrm{CoV}$ 2'-O-MTases. (A) Schematic presentation of the SARS-CoV-2 genome organization. Expression of two open reading frames (ORF1a and ORF1b) yields 16 nsps, including 2'-O-MTase nsp16. 
$\mathrm{S}, \mathrm{E}, \mathrm{M}$, and $\mathrm{N}$ indicate the four structural proteins spike, envelope, membrane, and nucleocapsid. (B) Sequence alignment of nsp16 proteins derived from genome sequences of the following: SARS-CoV-2, SARS-CoV-1, MERS-CoV, HCoV-OC43, HCoV-HKU1, HCoVNL63, and HCoV-229E. The secondary structure of SARS-CoV-2 nsp16 is shown above. Residues with 100\% conservation are indicated in solid red boxes and those with identity of 70\% or higher are depicted in light red color. The red stars indicate the conserved KDKE motif in 2'O-MTases. (C) Surface representation of the SAM binding pocket and the putative RNA binding groove in SARS-CoV-2 nsp16 with coloring according to the electrostatic potential. The surface electrostatic potential diagram ( $\pm 5 \mathrm{kT} / \mathrm{e})$ was generated by PyMol; the blue areas represent positively charged areas, while the red areas represent negatively charged areas. (D) The KDKE catalytic tetrad motif is located at the bottom of the RNA binding groove.

Figure 2: Comparison 2'-O-MTase domain of human CMTR1 with nsp16 of SARS-CoV-2. Top: Surface representation with electrostatic potentials showing the RNA binding groove and the SAM binding pocket of human CMTR1 (PDB: 4N48). Bottom: Superposition of the KDKE catalytic tetrad motifs of nsp16 of SARS-CoV-2 (PDB: 6W4H) and 2'-O-MTase domain of human CMTR1 (PDB: 4N48).

Figure 3. (A) Similarity chart of the 1380 best scored compounds for the SARS-CoV-2 nsp 16 using the FragFp descriptors in DataWarrior. Compounds with high chemical similarity are connected by lines. Stereoisomers of same drug such as Hesperidin (38 Stereoisomers) are clustered together. Compounds are colored according to their predicted AutoDock Vina score. (B) Neighbor tree shows seven drugs that have FragFp similarity scores greater than 0.8. Drugs are colored according to their FragFp similarity score to SAM. (C) Pie charts show target and pathway classes of hit compounds that were queried in the Probes and Drugs Portal.

Figure 4. Interaction of Hesperidin and Sonedenoson with SAM binding pocket of SARS-CoV-2 nsp16. Left: Surface representation with charge showing predicted binding of SARS-CoV-2 nsp16 with Hesperidin and Sonedenoson in the SAM binding pocket. Hesperidin and Sonedenoson are depicted by sticks. Middle: 3D representation of 2'-O-MTase active site 
residues interacting with Hesperidin and Sonedenoson. Right: 2D representation of 2'-O-MTase active site residues interacting with Hesperidin and Sonedenoson.

\section{Supplementary Figure Legends:}

Figure S1. The three-dimensional (3D) structures of nsp16s of SARS-CoV-2 (PDB: 6W4H) and MERS-CoV (PDB: 5YNM) were solved in complex with nsp10. RNA and SAM binding pockets were detected by DoGSiteScorer tool of the ProteinsPlus server.

Figure S2. The_RNA and SAM binding sites in nsp16 of MERS-CoV (PDB: 5YNM).

Figure S3. Interaction of Hesperidin and Sonedenoson with SAM binding pocket of SARS-CoV$2 \mathrm{nsp} 16$. Left: Surface representation with charge showing predicted binding of SARS-CoV-2 nsp16 with Osi-027 and Gs-9667 in the SAM binding pocket. Osi-027 and Gs-9667 are depicted by sticks. 3D representation of 2'-O-MTase active site residues interacting with Osi-027 and Gs9667. Right: 2D representation of 2'-O-MTase active site residues interacting with Osi-027 and Gs-9667. 
Table 1. Top ten scoring drugs for SARS-CoV-2 nsp16

\begin{tabular}{|c|c|c|c|c|c|c|}
\hline Drug Name & ZINC-ID & 2D Structure & $\begin{array}{l}\text { AutoDock } \\
\text { Vina Score } \\
\text { (Energy) }\end{array}$ & $\begin{array}{l}\text { Rosetta's } \\
\text { energy score } \\
\text { (REU) }\end{array}$ & Pharmacological Action & Clinical Stage \\
\hline Hesperidin & ZINC000100204053 & & -10.30 & -1502.394 & $\begin{array}{l}\text { Bioflavonoid with antioxidant, anti- } \\
\text { inflammatory, antiviral, and } \\
\text { anticarcinogenic properties. It is used } \\
\text { as a pharmaceutical raw material and } \\
\text { is one of the main components of a } \\
\text { Chinese medicine, beniol. }\end{array}$ & Phase 3/ Approved \\
\hline Rebastinib & ZINC000063933734 & & -10.20 & -1498.688 & $\begin{array}{l}\text { Inhibitor of Tie2 tyrosine kinase } \\
\text { receptor and an antineoplastic agent. } \\
\text { Treatment of locally advanced or } \\
\text { metastatic solid tumor. }\end{array}$ & Phase 2 \\
\hline Losulazine & ZINC000004216779 & & -10.27 & -1497.669 & Antihypertensive agent & Phase 0 \\
\hline Cep-32496 & ZINC000043207440 & & -10.20 & -1497.019 & $\begin{array}{l}\text { Inhibitor of BRAF(V600E/WT) and c- } \\
\text { Raf. Treatment of advanced lung } \\
\text { cancer and other solid tumors. }\end{array}$ & Phase 1 \\
\hline $\mathrm{R} 428$ & ZINC000051951669 & & -10.40 & -1495.172 & $\begin{array}{l}\text { Inhibitor of the tyrosine-protein kinase } \\
\text { receptor UFO. Treatment of solid } \\
\text { tumors. }\end{array}$ & Phase 2 \\
\hline Entrectinib & ZINC000043204146 & & -10.57 & -1494.424 & $\begin{array}{l}\text { Pan-Trk, ROS1, and ALK inhibitor. } \\
\text { Treatment of ROS1-positive } \\
\text { metastatic non-small cell lung cancer } \\
\text { and NTRK gene fusion positive solid } \\
\text { tumors }\end{array}$ & Approval \\
\hline Osi-027 & ZINC000252286769 & & -10.50 & -1492.853 & $\begin{array}{l}\text { An organic compound that functions } \\
\text { as a dual inhibitor of mTORC1 and } \\
\text { mTORC2. Treatment of any solid } \\
\text { tumor or lymphoma. }\end{array}$ & Phase 1 \\
\hline MK3207 & ZINC000043203371 & & -10.97 & -1491.611 & $\begin{array}{l}\text { A CGRP receptor antagonist. } \\
\text { Treatment of migraine. }\end{array}$ & Phase 2 \\
\hline Rimegepant & ZINC000068267814 & & -10.77 & -1486.358 & $\begin{array}{l}\text { An oral antagonist of the CGRP } \\
\text { receptor. Treatment of migraine. }\end{array}$ & approval \\
\hline Bolazine & ZINC000008214506 & & -10.47 & -1484.411 & $\begin{array}{l}\text { A synthetic androgen/anabolic steroid } \\
\text { of the dihydrotestosterone group }\end{array}$ & \\
\hline
\end{tabular}


Table 2. Seven drugs chemically similar to natural ligand (SAM) of nsp16 2'-O-Mtase and SAM

\begin{tabular}{|c|c|c|c|c|c|c|}
\hline Drug Name & ZINC-ID & 2D Structure & $\begin{array}{c}\text { AutoDock } \\
\text { Vina Score } \\
\text { (Energy) }\end{array}$ & $\begin{array}{l}\text { Rosetta's } \\
\text { energy score } \\
\text { (REU) }\end{array}$ & Pharmacological Action & Clinical Stage \\
\hline Gs-9667 & ZINC000256680330 & & -8.87 & -1499.573 & $\begin{array}{l}\text { Adenosine receptor A1 agonist. } \\
\text { Treatment of type } 2 \text { diabetes. }\end{array}$ & Phase 1(?) \\
\hline Sonedenoson & ZINC000003966398 & & -8.30 & -1494.485 & $\begin{array}{l}\text { Natural product and adenosine } \\
\text { receptor A2a agonist. Treatment of } \\
\text { foot ulcer, diabetes, and diabetic } \\
\text { complications. }\end{array}$ & Phase 2 \\
\hline Regadenoson & ZINC000003598383 & & -8.33 & -1491.72 & $\begin{array}{c}\text { Adenosine receptor } \mathrm{A} 2 \mathrm{a} \text { agonist. } \\
\text { Diagnostic agent for radionuclide } \\
\text { myocardial perfusion imaging. }\end{array}$ & approval \\
\hline Metrifudil & ZINC000004216929 & & -8.20 & -1491.61 & $\begin{array}{l}\text { Synthetic adenosine analog. } \\
\text { Antihypertensive agent. }\end{array}$ & Phase 0 \\
\hline Binodenoson & ZINC000003932652 & & -8.57 & -1490.97 & $\begin{array}{c}\text { Adenosine receptor } \mathrm{A} 2 \mathrm{a} \text { agonist. } \\
\text { Diagnostic agent for coronary artery } \\
\text { disease. }\end{array}$ & Phase 2 \\
\hline Trabodenoson & ZINC000214055339 & & -8.40 & -1489.93 & $\begin{array}{l}\text { Adenosine receptor A1 agonist. } \\
\text { Treatment of ocular hypertension and } \\
\text { primary open-angle glaucoma. }\end{array}$ & Phase 2 \\
\hline Selodenoson & ZINC000003989599 & & -8.10 & -1489.55 & Adenosine receptor $\mathrm{A} 1$ agonist. & Phase 0 \\
\hline $\begin{array}{l}\text { S-adenosyl-methionine } \\
\text { (SAM) }\end{array}$ & ZINC000004214738 & & -8.1 & -1509.654 & Natural ligand of 2'-O-MTase & \\
\hline
\end{tabular}


Figure 1

A

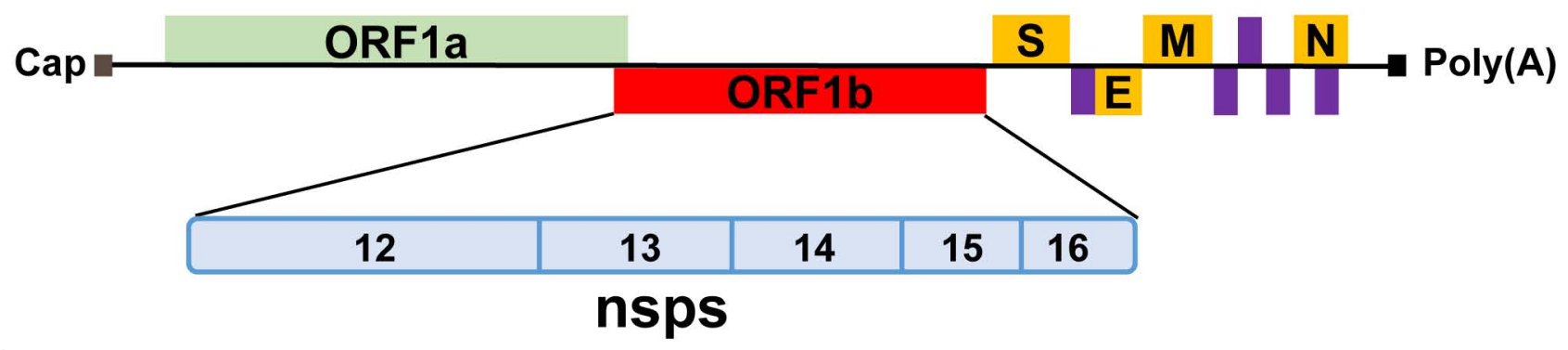

B

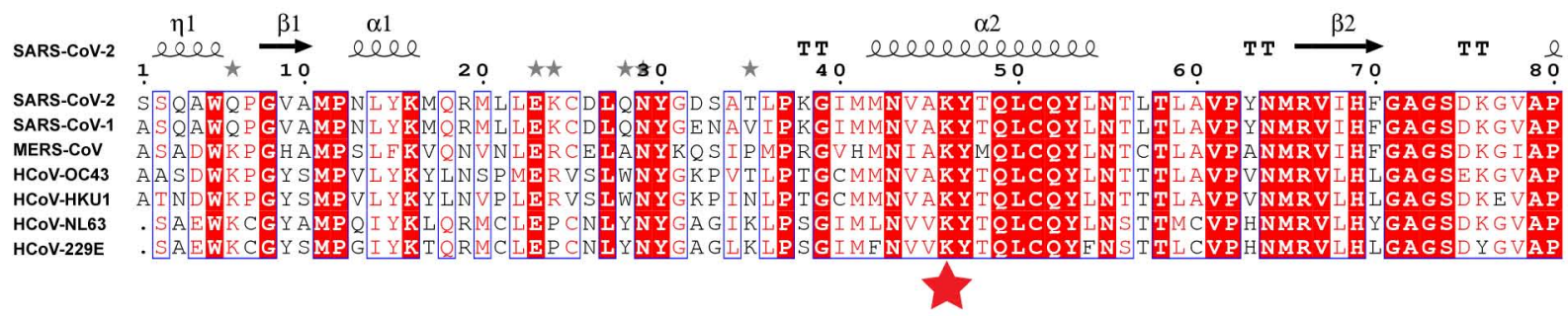

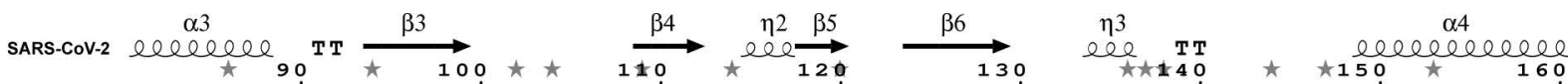

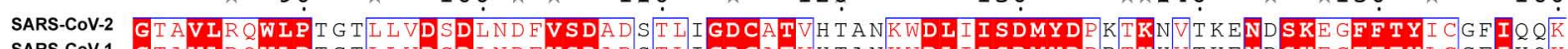
SARS-CoV-1 GTAVLRQWLPTGTLLVDSDINDFVSDADSTLIGDCATVH TANKWDIIISDMYDPRTRHVTKENDSKEGFTTYLCGFIKQK MERS-COV GTSVLRQWLPTDAII IDNDLNEFVSDADITLF GDCVTVRVG Q QVDIVI SDMYDPTTKNVTGSNESKALFFTYLCNLINNN HCoV-OC43 GSAVIROWLPAGTILVDNDLYPFVSDSVATYEGDCITIPFDCOWDIII SDMYDP ITKNIGEYNVSKD GFFTYICHMIRDK HCOV-HKU1 GS AVLROWLPSGSILVDNDLNPFVSDSLVTYF GDCMTIPFDCHWDIII SDMYDP LTKNIGDYNVSKDGFFTYICHLIRDK

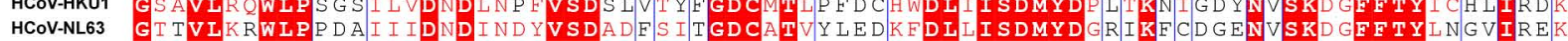

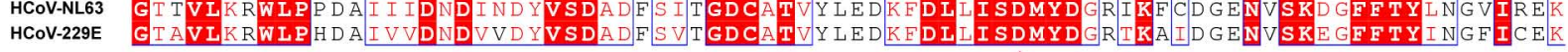
$\hat{1}$

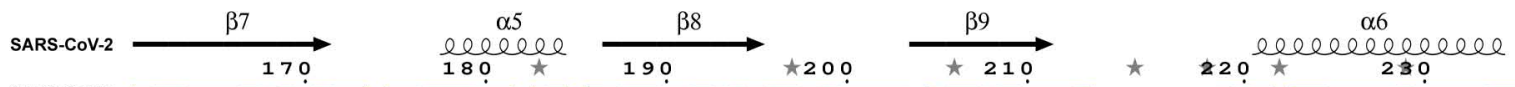

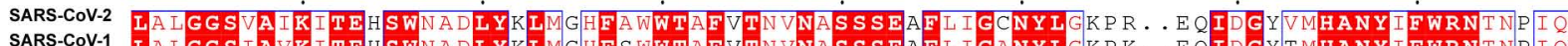

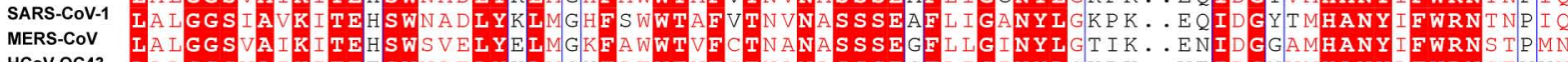

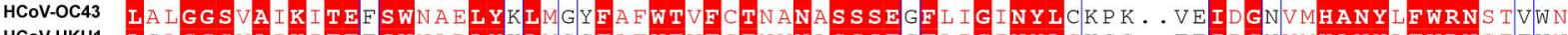

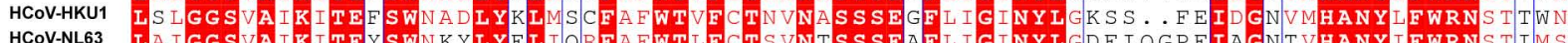
HCOV-229E LAIGGSIAIKVTEYSWNKKLYELVQRESEWTMECTSVNISS SEAEVVGINYLGD AQGPFIDGNIIHANYVEWRNSIVMS

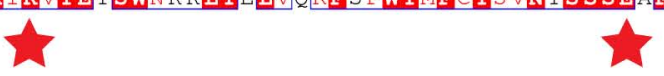

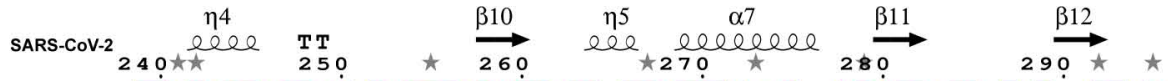

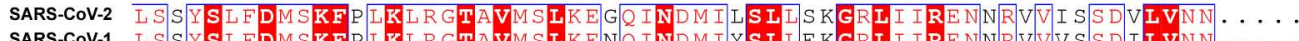

MERS-CoV LSTYSLEDLSKFOLKLKGTPVLOLKESQINELVISLLSOGKLIIRDNDTLSVST TVIVNTYRKLR

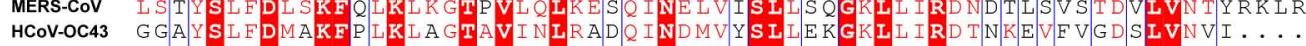

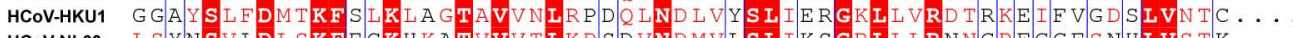

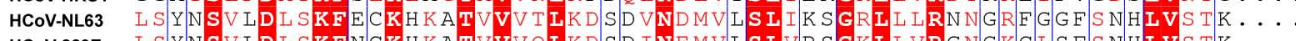

HCoV-229E ISYNSVLDLSKFNCKHKATVVVQLKDSDINEMVLSLVRSGKLIVRGNGECLSFSNHLVSTK . . .
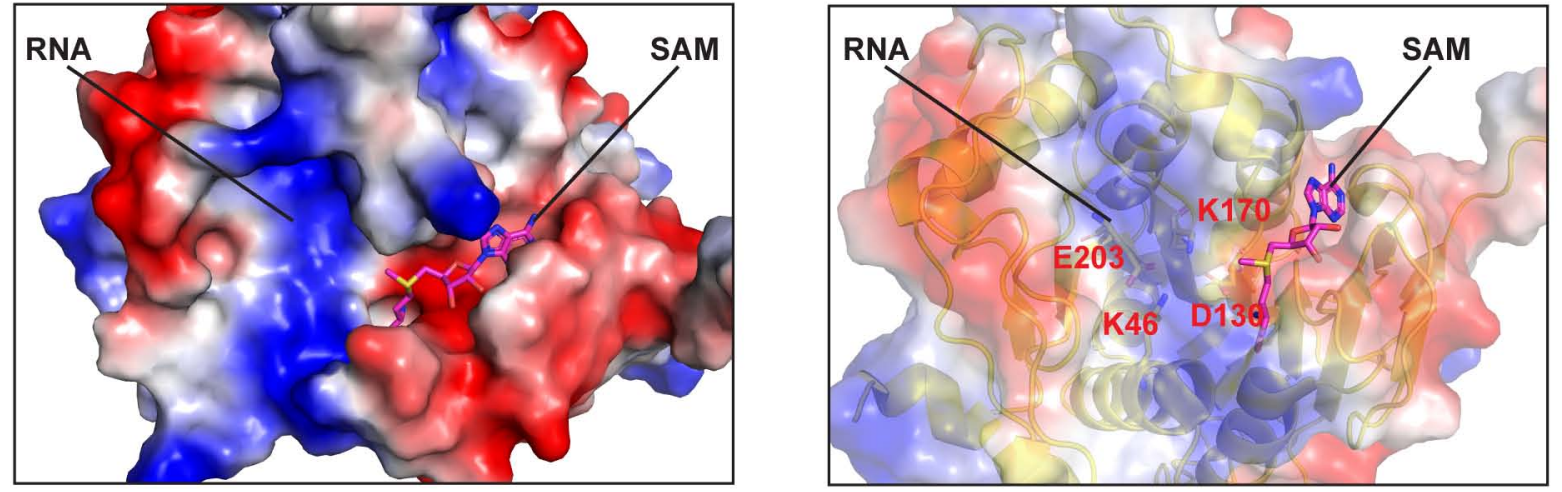
Figure 2
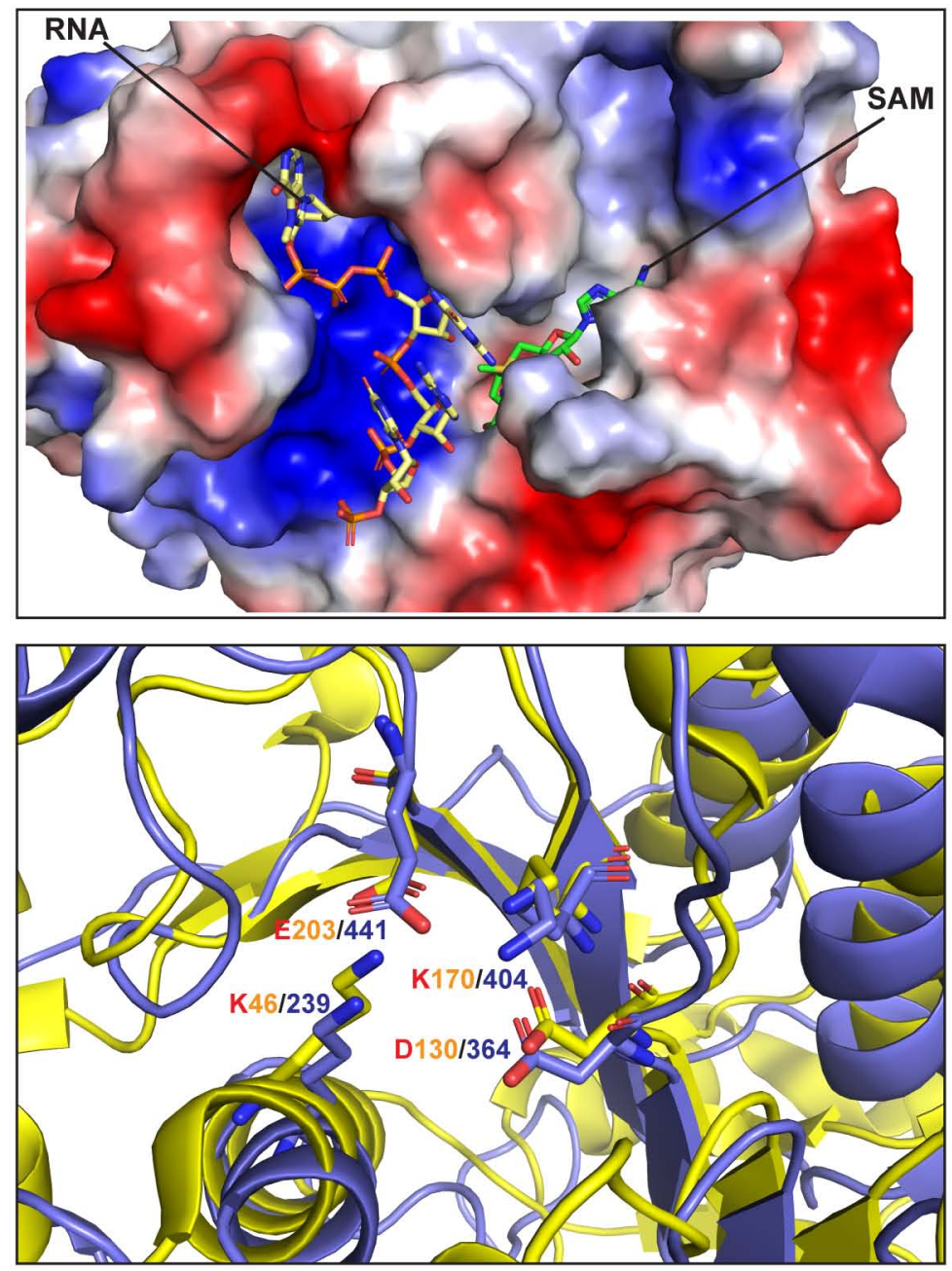


\section{Figure 3}

A

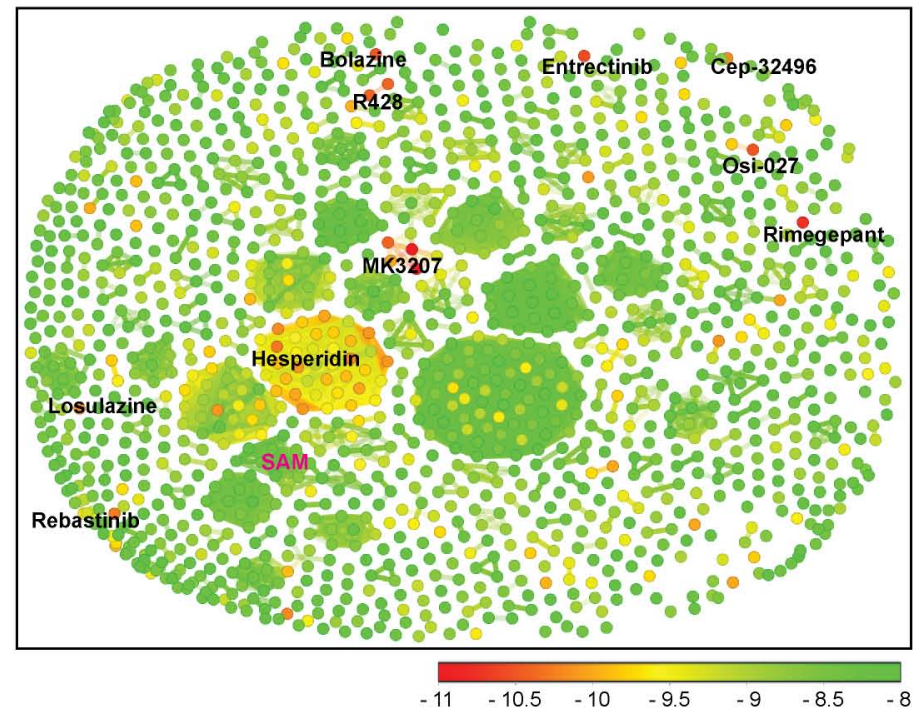

C

\section{Target Classes}

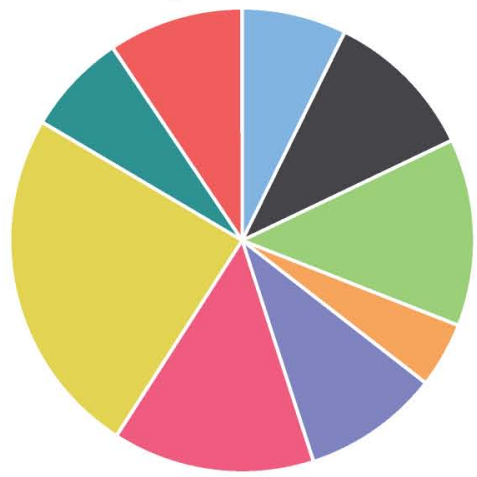

Epigenetic regulator

Kinases (EC 2.7.x.x)

Ion channels

G protein-coupled receptors

Transporters

Peptidases and proteinases

Catalytic receptors

Nuclear hormone receptors
B

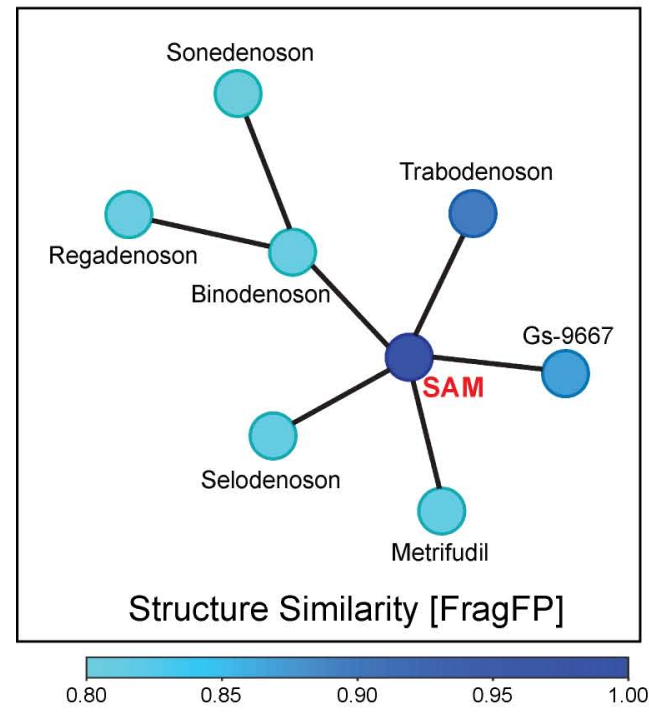

Pathway Classes

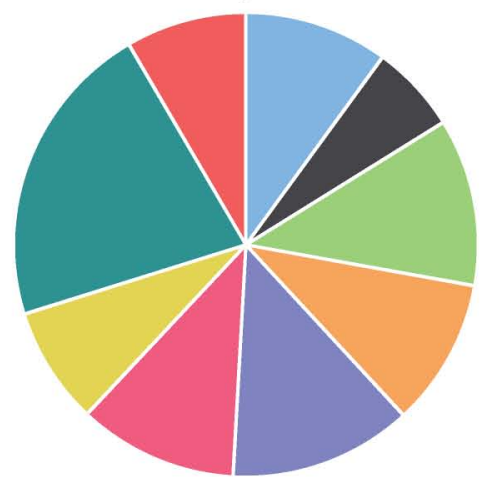

Developmental Biology

Cellular responses to stress

Gene expression (Transcription)

Immune System

Hemostasis

Neuronal System

Metabolism of proteins

Cell Cycle 
Figure 4

Hesperidin
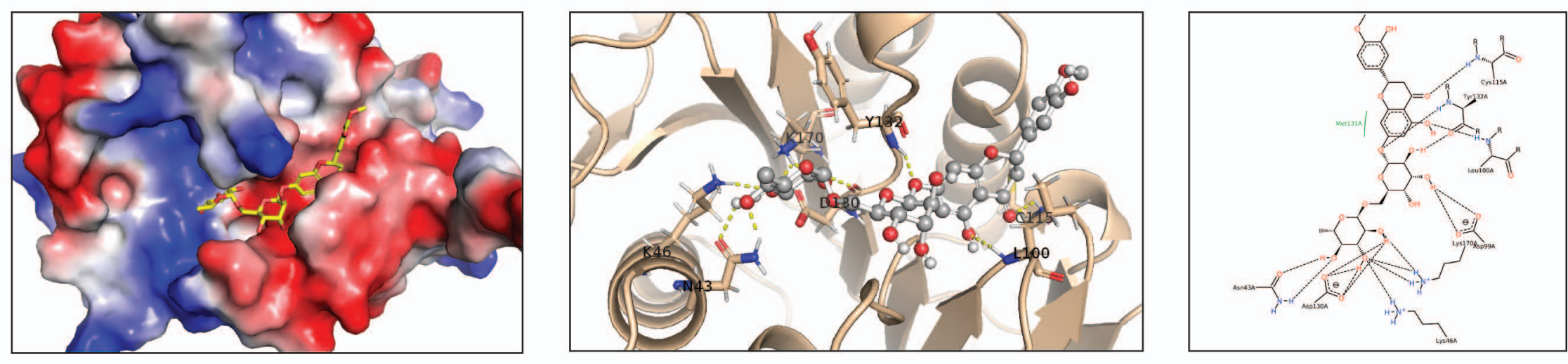

\section{Sonedenoson}
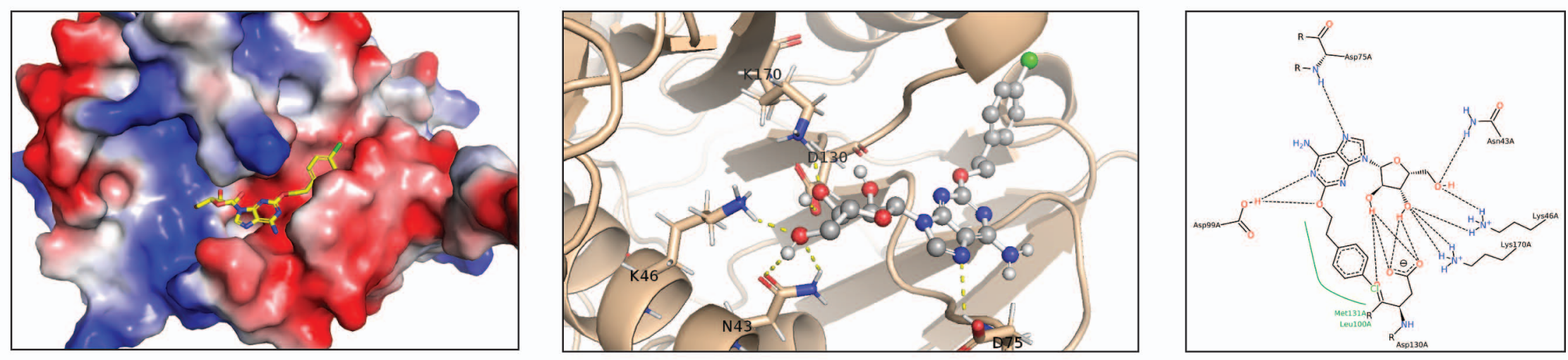